\title{
Monitoring and Simulation of Dynamic Spatiotemporal Land Use/Cover Changes
}

\author{
Andong Guo $\mathbb{D}$, ${ }^{1}$ Yuqing Zhang $\mathbb{D}$, ${ }^{1}$ and Qing Hao $\mathbb{i D}^{2}$ \\ ${ }^{1}$ Human Settlements Research Center, Liaoning Normal University, 116029 Dalian, China \\ ${ }^{2}$ Institute of Ecological Civilization Study, Chinese Academy of Social Sciences, Beijing, China \\ Correspondence should be addressed to Yuqing Zhang; zhangyuqing@lnnu.edu.cn and Qing Hao; haoq.16b@igsnrr.ac.cn
}

Received 13 April 2020; Revised 12 May 2020; Accepted 29 May 2020; Published 27 June 2020

Guest Editor: Jianhong Cecilia Xia

Copyright (C) 2020 Andong Guo et al. This is an open access article distributed under the Creative Commons Attribution License, which permits unrestricted use, distribution, and reproduction in any medium, provided the original work is properly cited.

Changes in land use/cover are among the most prominent impacts that humans have on the environment. Therefore, exploring land use/cover change is of great significance to urban planning and sustainable development. In this study, we preprocessed multiperiod land use and socioeconomic data, combined with spatial zoning, multilayer perception (MLP) artificial neural network, and Markov chain (MC), to construct a cellular automaton model of spatial zoning. Moreover, with the help of ArcGIS 10.2 and TerrSet 18.07 software, we explore the current status of land use and predict future changes. The results showed that drastic changes have occurred among different land use classes in Jinzhou District over the past 13 years owing to the impact of economic development and reclamation projects. Construction land, arable land, and waters have changed by $+85.09,-24.42$, and $-23.62 \mathrm{~km}^{2}$, respectively. By comparing the FoM and Kappa coefficients, we concluded that the prediction accuracy of partitioned MLP-MC is better than that of unpartitioned MLP-MC. Therefore, using the spatial zoning approach to identify the conversion rules among land use classes in different zones can more effectively predict future land use changes and provide a reference for urban planning and policy making.

\section{Introduction}

With rapid global urbanization and constant economic and population growth, the human demand for natural resources continue to increase, resulting in a dramatic evolution of land use/cover changes (LUCC) and an array of ecoenvironmental problems, such as arable land loss, urban heat island effect, air pollution, urban ventilation, and decline in biodiversity [1-5]. Therefore, understanding the characteristics of urban expansion and rational planning of land use through monitoring and simulations are vital for the sustainable development of cities and the improvements in regional coordination.

Cities are complex systems with dynamic, self-organizing, and nonlinear characteristics [6-9]. With the developments in remote sensing and geographic information systems (GIS), more effective tools are available for the analysis of LUCC [10-13]. Multitemporal land use data can be rapidly collected from remote sensing images to examine the evolution of land use, which provides strong evidence for predicting the future dynamic characteristics $[14,15]$. There are numerous theories and models that have been applied to LUCC simulations, such as system dynamics (SD), multiagent system (MAS), cellular automata, conversion of land use and its effects (CLUE), and SLEUTH model (slope, land use, exclusion, urban extent, transportation, and hillshade) [16-19]. Different models have their own theoretical frameworks, which provide a basis for the improved exploration of the characteristics of urban spatial complexity. Among them, the cellular automata (CA) method is widely used in land use/cover simulations.

Cellular automata, one of the most effective tools for simulating the dynamic characteristics of complex systems, are widely used in the complex mechanisms associated with urban development and have become a vital tool for land use planning and management [20-23]. Cellular automata are mainly composed of cells, cellular space, conversion rules, and neighborhood configuration. Conversion rules are 
defined to determine the dynamic function of the cellular state at the next moment according to the current state of the cell and neighborhood, which is an important part of the cellular automata [24-26]. However, conversion rules in urban growth involve a complex process of dynamic and nonlinear human-nature interactions, which are difficult to monitor using the standard and unified methods. Thus, to reflect the growth process of different cities and improve the accuracy of urban expansion simulations, various methods have been applied for calibrating conversion rules, such as Markov-CA [27], logistic regression (logistic-CA) [28], multicriteria evaluation (MCE-CA) [29], support vector machine (SVM-CA) [30], artificial neural network (ANNCA) [31], spatial regression [32], fuzzy set algorithm [33], and random forest (RF-CA) [34].

There are numerous integrated methods for LUCC simulations, but the unified conversion rules are mostly applied to simulate the complex characteristics of cities, and ignoring the spatial heterogeneity characteristics is easy. As factors such as geographical features and socioeconomic affect urban spatial growth, cities display the characteristics of multilevel and spatial heterogeneity such that the spatial growth patterns of different regions within the city vary dramatically. Therefore, using unified conversion rules to simulate the cellular state is difficult [35]. To address this problem, based on factors such as geographical characteristics, transportation, population, and social economy, previous studies have adopted methods including gravity model and spatial clustering for spatial zoning and followed the zoning approach to identify the regional growth characteristics and conversion rules, thereby increasing the prediction accuracy $[36,37]$.

However, researchers generally use administrative units for spatial clustering for spatial zoning and lack of division based on the actual land change characteristics of the region. Therefore, according to the complexity and heterogeneity of urban space, a reasonable division of geographic space can effectively grasp the law of urban development. In this paper, we aim to use spatial zoning and cellular automata to identify the conversion rules of each area to simulate future land use changes and improve simulation accuracy. The approach of this study can be summarized as follows: (1) explore the dynamic evolution of land use in Jinzhou District in the past 13 years and analyze its spatial growth pattern; (2) divide the study area with a spatial zoning approach to identify the land use transition potential of each zone; (3) adopt zoned and nonzoned MLP-MC models to predict land use changes and validate the models.

\section{Study Area}

Jinzhou District is situated in the southern Liaodong Peninsula, bordering the Yellow and Bohai seas. Located in the Bohai Economic Rim (BER) and Northeast Asia Economic Rim, Jinzhou is an important area of the city of Dalian. The district has 25 streets and has a solid foundation for development, owing to the Jinshitan National Holiday Resort, a $5 \mathrm{~A}$-Class national tourist attraction. Jinzhou District has a warm and semihumid monsoon climate with oceanic climate characteristics and thus it is comfortably habitable all year round. Recent urban expansion of Dalian has driven the economic growth of Jinzhou District further, resulting in considerable changes in its urban land use pattern. Therefore, analysis and simulation of the dynamic LUCC in the district can provide reference for spatial layout planning and urban management. The location of the study area is shown in Figure 1.

\section{Materials and Methods}

The future LUCC were predicted by combining spatial zoning with the MLP-MC model, which includes data preprocessing, spatial zoning, MLP-MC construction, and model validation steps. The steps in spatial zoning and MLPMC model validation are shown in Figures 2(a) and 2(b), respectively.

\subsection{Data Preprocessing}

3.1.1. Data Sources. The data used in the models include land use, digital elevation model (DEM), road network, point of interests (POIs), population, and planning data. Among them, land use, roads, planning, and administrative boundaries have been obtained from the Dalian Land Resources and Housing Bureau. The coastline is obtained by the SPOT 5 remote sensing image extraction. See Table 1 for other data descriptions. According to the land use data and the land use classification standard, that is, GB/T 21010-2017 [38], we classified the land use into six types: construction land, arable land, forestland, garden, waters, and other land (Table 2), which were resampled to a grid of $30 \times 30 \mathrm{~m}$.

3.1.2. Influencing Variables. Many factors such as natural characteristics, social economy, and planning affect the dynamic LUCC. Considering the previous selection of LUCC variables and data validity in Jinzhou District [39-42], we divided the influencing variables of LUCC into three categories: natural characteristics, socioeconomic, and land use planning variables, which include 12 factors such as DEM and slope (Table 3). All variables were then normalized to the range of $[0,1]$ to facilitate the subsequent analysis of the relationship between land use changes and influencing variables.

3.2. Spatial Zoning. The land use changes of local units are affected by the location and natural characteristics of local units, as well as socioeconomic factors, which cause dramatic differences in the spatial growth of the urban areas. Therefore, the adoption of globally unified land use conversion rules fails to conform to the development characteristics of each region. To address this limitation, previous studies have adopted methods such as the gravity model and spatial clustering for zoning simulations. Spatial zoning aims to improve the simulation accuracy $[43,44]$. Current zoning approaches are largely based on geographical administrative units such as prefectures and counties. However, zoning by 

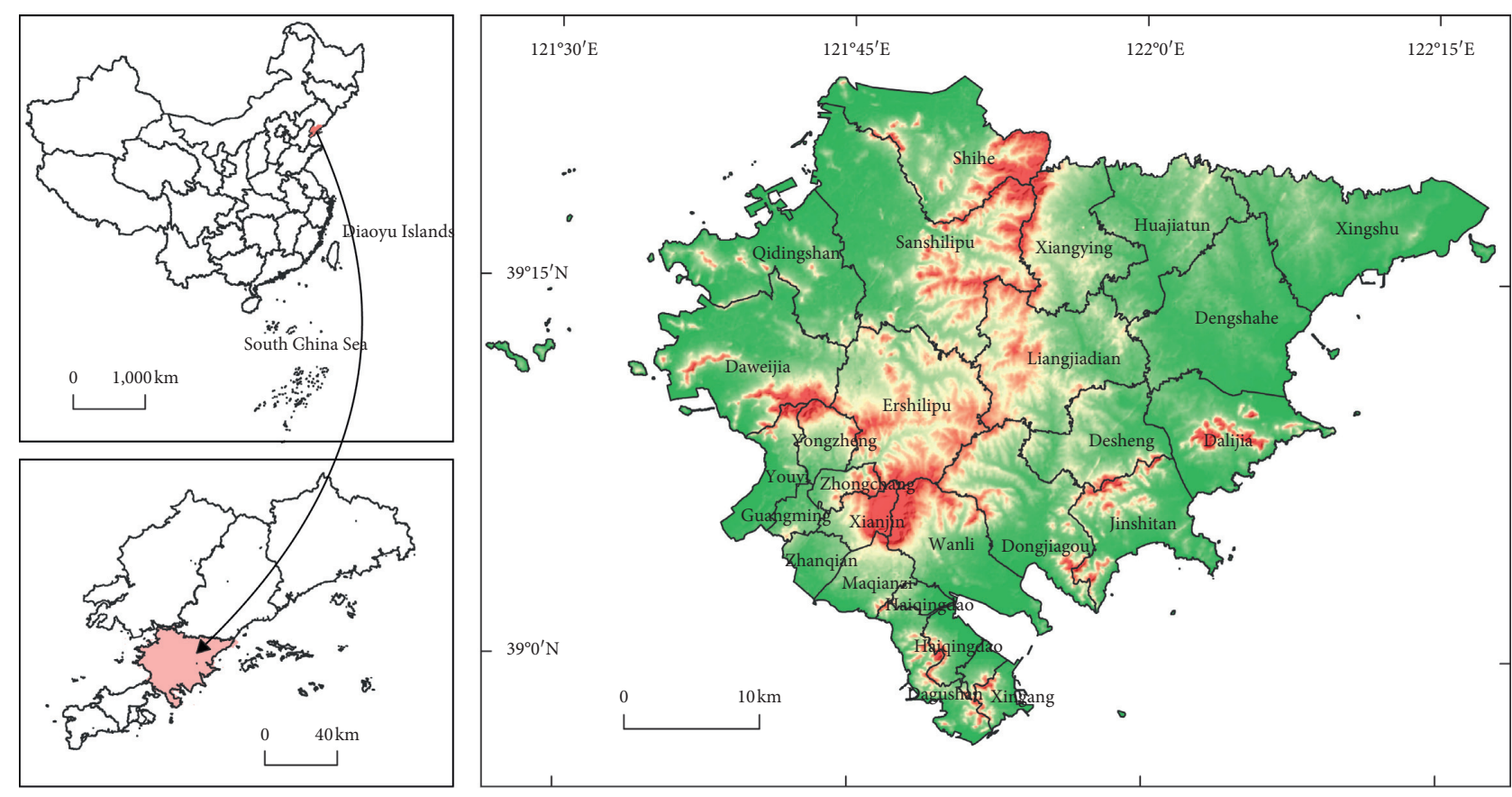

DEM

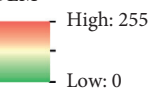

Figure 1: Location of the study area.

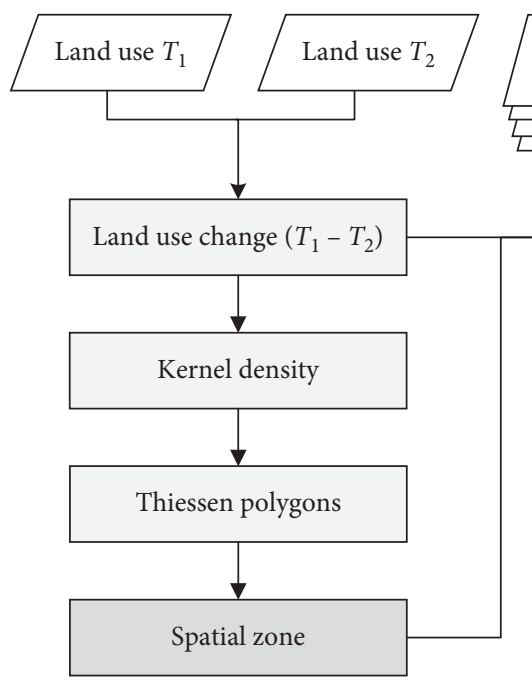

(a)

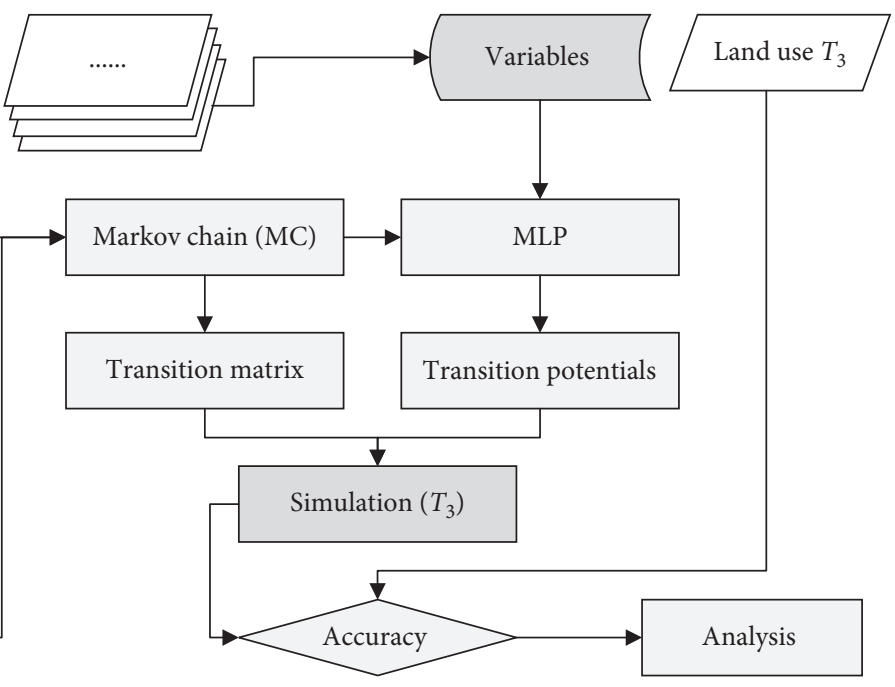

(b)

Figure 2: Land use simulation process. (a) Spatial zone. (b) MLP-MC.

TABle 1: Data source and description.

\begin{tabular}{lcc}
\hline Type & Data features & Description \\
\hline Land use data & Polygon vector data $(1: 10000)$ & Dalian land resources and housing bureau \\
DEM & Raster data $(30 \mathrm{~m})$ & Geospatial data cloud (http://www.gscloud.cn) \\
Coastline & Line vector data & Extraction through SPOT 5 remote sensing image \\
Road & Line vector data $(1: 10000)$ & Dalian land resources and housing bureau \\
POIs & Leisure, public, and government points & Baidu map open platform \\
Population density & Statistics of each street & Jinzhou statistical yearbook \\
Administrative boundary & Vector data & Dalian land resources and housing bureau \\
Planning data & Txt and jpg & Dalian land resources and housing bureau \\
\hline
\end{tabular}


TABLE 2: Description of land use classification.

\begin{tabular}{|c|c|}
\hline Type & Description \\
\hline Construction land & $\begin{array}{c}\text { Refers to land used for urban and rural housing and public facilities, including land for transportation, commercial } \\
\text { services, and industrial and mining storage }\end{array}$ \\
\hline Arable land & Refers to the land where crops are grown, including dry land, irrigated land, and paddy field \\
\hline Forestland & Refers to land for growing trees, bamboos, and shrubs, including shrub land, forestland, and other forestland \\
\hline Garden & Refers to planting land mainly for collecting fruits, leaves, roots, stems, and so forth, including orchard, tea garden \\
\hline Waters & Refers to land and water areas, beaches, ditches, hydraulic structures, and other land \\
\hline Other land & Refers to land other than the above, including bare land, sandy land, and saline land \\
\hline
\end{tabular}

TABLE 3: Description of influencing variables.

\begin{tabular}{|c|c|c|}
\hline Type & Variable & Description \\
\hline Natural characteristics & $\begin{array}{c}\text { Dem }\left(X_{1}\right) \\
\text { Slope }\left(X_{2}\right) \\
\text { Distance from coastline }\left(X_{3}\right) \\
\end{array}$ & $\begin{array}{c}\text { DEM }(\mathrm{m}) \\
\text { Slope }\left(^{\circ}\right) \\
\text { Euclidean distance from coastline }(\mathrm{m})\end{array}$ \\
\hline Socioeconomic & $\begin{array}{c}\text { Distance river }\left(X_{4}\right) \\
\text { Distance road }\left(X_{5}\right) \\
\text { Distance railway }\left(X_{6}\right) \\
\text { Distance from administrative center }\left(X_{7}\right) \\
\text { Distance from public service }\left(X_{8}\right) \\
\text { Distance leisure and entertainment }\left(X_{9}\right) \\
\text { Population density }\left(X_{10}\right) \\
\end{array}$ & $\begin{array}{c}\text { Euclidean distance from river }(\mathrm{m}) \\
\text { Euclidean distance from main road }(\mathrm{m}) \\
\text { Euclidean distance from railway }(\mathrm{m}) \\
\text { Euclidean distance from administrative center }(\mathrm{m}) \\
\text { Euclidean distance from public service point }(\mathrm{m}) \\
\text { Euclidean distance from leisure and entertainment point }(\mathrm{m}) \\
\left.\text { Population density of each street (person } / \mathrm{km}^{2}\right)\end{array}$ \\
\hline Land use and planning & $\begin{array}{l}\text { Farmland reserve }\left(X_{11}\right) \\
\text { Ecological reserve }\left(X_{12}\right)\end{array}$ & $\begin{array}{l}0 \text { for reserve and } 1 \text { for other areas } \\
0 \text { for reserve and } 1 \text { for other areas }\end{array}$ \\
\hline
\end{tabular}

administrative units tends to overlook the problem of spatial heterogeneity [45].

Urban growth is a complex and nonstationary spatial process, with predictions that must include spatiotemporal heterogeneity. In the process of land use simulation, conversion rules should be dynamically adjusted for different regions and time periods. The Thiessen polygon is a type of subdivision of the space plane. Each position in the polygon is the closest to the sample point of the polygon. Because of its equipartition feature in space segmentation, it is mostly used in spatial analysis problems, such as in adjacency, proximity, and accessibility analysis $[46,47]$. Therefore, we used Thiessen polygons for irregular spatial zones to improve the prediction accuracy. The process can be described as follows. First, we extracted the changed region based on the initial and final stages of land use. Then, we conducted a kernel density analysis on regions with land use changes and selected the points where the change was more concentrated using the kernel density map and the actual development characteristics of each region. Finally, we created Thiessen polygons according to the selected points to achieve spatial zoning.

3.3. MLP-MC Model. The MLP-MC model consists of MLP and MC $[48,49]$. MLP is used to obtain the spatial distribution of the land use transition potential. Transition potential refers to the probability of predicting the transition among land use classes, which depends on the explanatory power that driving factors have on land use changes. Higher transition probability indicates higher conversion suitability of one land use class into another $[50,51]$. MC, which has been extensively applied to LUCC modelling, defines the changing trend of each specific land use class from the past to the present and to the future and is thus used to obtain the transition area or transition probability matrix $[52,53]$.

MLP adopts the multilayer perceptual neural network classifier based on the backpropagation (BP) algorithm. Apart from remote sensing image classification, the MLP model can also be applied to manage the nonlinear relationships among variables, which can simultaneously handle multiple models and convert the input data into the desired output of complex mathematical functions [54-56]. In our study, the MLP model provides a neuron (transition potential) as the output by performing nonparametric regression analysis between an input variable and dependent variable. The MLP model contains an input layer, hidden layer, and output layer (Figure 3), which represent the land use changes and the influencing factors, data calculation and processing, and transition potential, respectively. Moreover, the relationships between the variables and land use changes can be explained by Cramer's V $[57,58]$. The higher the value, the better the fit between the variables and land use changes. In this study, the MLP-MC model is specifically implemented using the LCM function in TerrSet software (version 18.07):

$$
\text { Cramer's } V=\sqrt{\frac{x^{2}}{n \times(\min \{a, b\}-1)}},
$$

where $x^{2}$ represents the Pearson's chi-square statistic, $n$ represents the number of data, $a$ and $b$ represent the number of rows and columns of the matrix, and $\min \{a, b\}$ represents the smaller value of $a$ and $b$. 


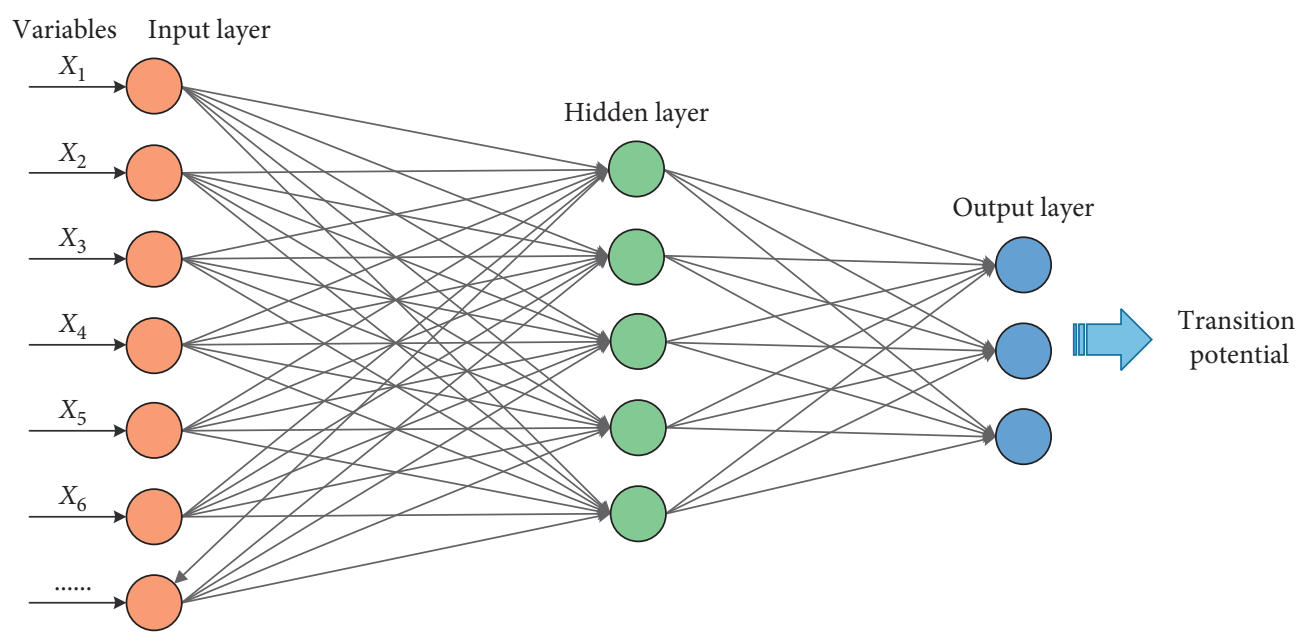

FIgURE 3: MLP analysis structure.

3.4. Model Validation. The validation of land use predictions is a major part of the CA model. Primary parameters for validation are the figure of merit (FoM), overall accuracy, and Kappa coefficient [59-61]. We employed the FoM and Kappa coefficient to more directly validate the accuracy of the model predictions. The FoM was derived from the superposition of recent land use, predicted land use, and actual land use data and can be expressed as follows:

$$
\text { FoM }=\frac{A}{A+B+C},
$$

where $A$ represents the hits (i.e., the model predicted the change and LUCC did change), $B$ denotes misses (i.e., the model predicted persistence and LUCC did change), and $C$ indicates false alarms (i.e., the model predicted the change and LUCC persisted).

Kappa is an index for evaluating the accuracy of multiclass land use simulations and predictions $[62,63]$. The result derived from the confusion matrix, that is, the superposition of the land use simulation results and actual land use data, can be expressed as follows:

$$
\text { Kappa }=\frac{P o-P c}{P p-P c},
$$

where $P_{o}$ is the proportion of correct simulations, $P_{c}$ is the expected proportion of correct simulations in random cases, and $P_{p}$ is the proportion of correct simulations for an ideal classification case. In general, a value greater than 0.7 indicates high accuracy.

\section{Results}

4.1. Spatiotemporal Land Use Change. Figure 4 shows the main land use classes in Jinzhou District, that is, arable land, construction land, and forestland. By 2016, the proportions of these three land use classes were $26.88,30.81$, and $22.48 \%$, respectively. Because of economic development, population increase, and reclamation projects, construction land showed an increasing trend and scattered spatial distribution, concentrated in the southern and coastal areas such as
Maqinzi Street, Haiqingdao Street, Zhanqian Street, and Wanli Street. Forestland showed a narrow and strip-shaped distribution, mostly along the coastal streets.

To further examine the transition characteristics of each land class, the land use transition matrix from 2004 to 2016 was calculated (Table 4). Table 4 shows that, in the past 13 years, the construction land in Jinzhou District has increased by $85.09 \mathrm{~km}^{2}$, whereas arable land, garden, waters, and forestland have decreased by 24.42, 21.79, 23.62, and $13.88 \mathrm{~km}^{2}$, respectively. Arable land, waters, forestland, and garden have been transformed to construction land in the order of $27.16,25.97,19.88$, and $17.91 \mathrm{~km}^{2}$, respectively. The waters have been largely reduced due to the impact of reclamation projects. Apart from the transition of each land class to construction land, other large-area land transitions have been arable land and garden to forests by 5.24 and $6.48 \mathrm{~km}^{2}$, respectively, and forests and garden to arable land by 5.57 and $4.70 \mathrm{~km}^{2}$, respectively.

4.2. Spatial Zoning. Due to the differences in the transition patterns of land use classes in different regions of the city, applying unified conversion rules to simulate future changes tends to produce large errors in the results. Thus, we followed the spatial zoning approach to perform spatial analysis to acquire land use characteristics and conversion rules in each zone. First, we extracted the regions with spatial changes in land use from 2008 to 2012 to conduct a kernel density analysis (Figure 5(a)). Then, we created point elements in the regions with large changes according to the kernel density and development characteristics of each region. Finally, we created Thiessen polygons according to the generated points to obtain the zoning results (Figure 5(b)). The study area was divided into 17 regions.

\subsection{Prediction and Validation of Land Use}

4.3.1. Driving Factors and Transition Potential. The MLP reviewed the relationships between land use changes and influencing variables to process the training samples and 


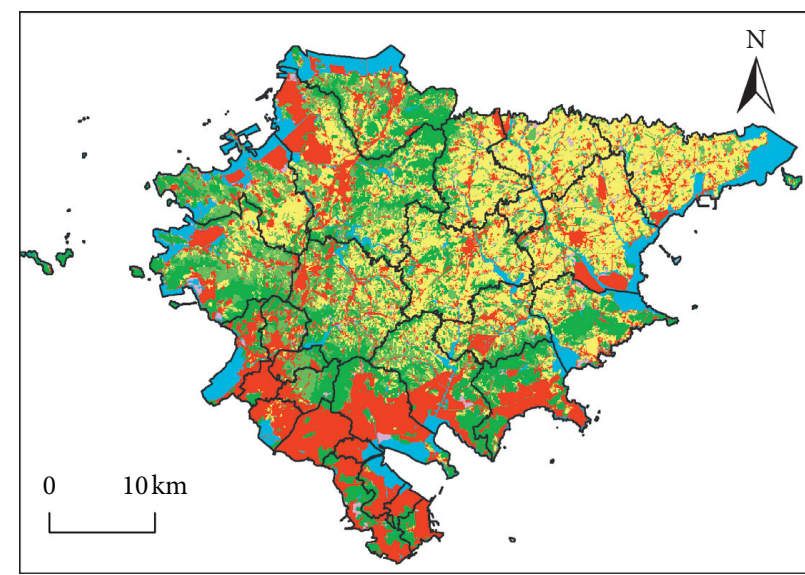

Construction land

Forestland

Arable land

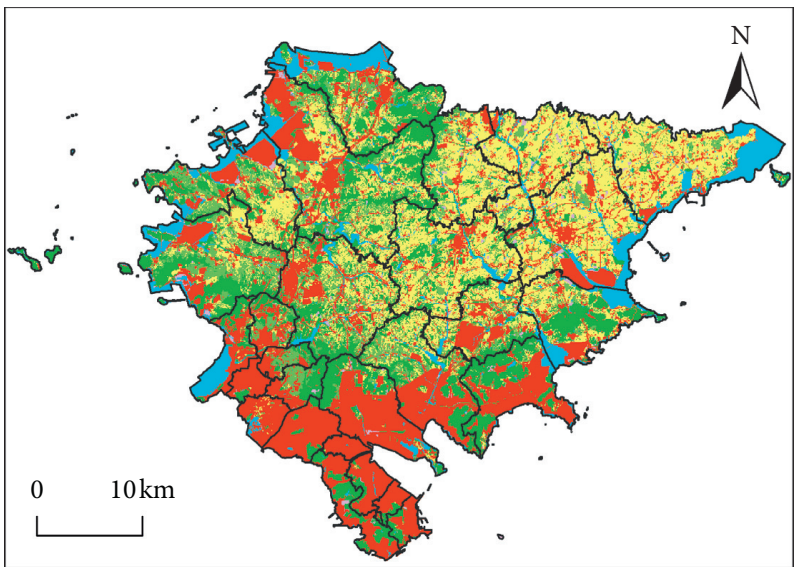

Construction land

Forestland

Arable land
Other lands

Waters

Garden

(a)

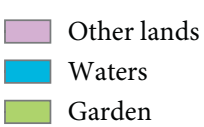

(c)

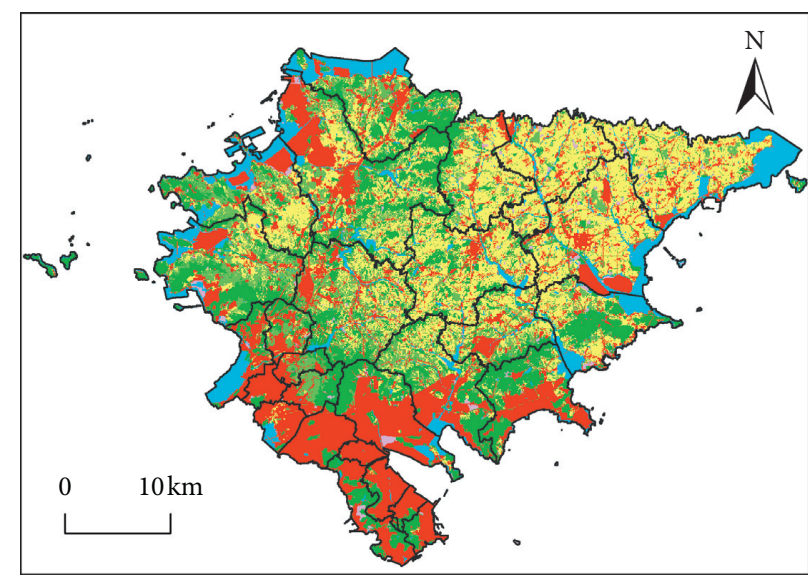

Construction land

Forestland

Arable land

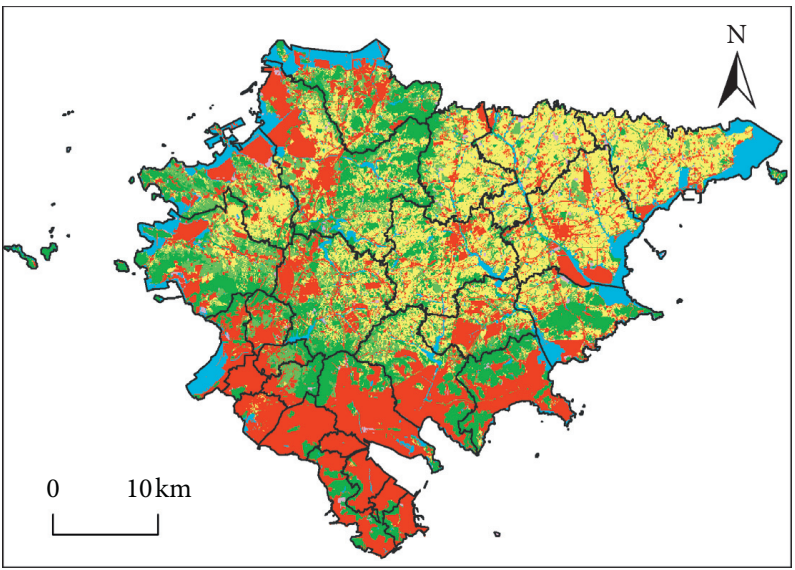

Construction land

Forestland

Arable land
Other lands

Waters

Garden

(d)

Figure 4: Land use change: (a) 2004, (b) 2008, (c) 2012, and (d) 2016.

TABLE 4: Land use transfer matrix (2004-2016) (unit: $\mathrm{km}^{2}$ ).

\begin{tabular}{|c|c|c|c|c|c|c|c|}
\hline Type & Construction land & Forestland & Arable land & Garden & Other land & Waters & 2016 total \\
\hline Construction land & 360.04 & 19.88 & 27.16 & 17.91 & 3.40 & 25.97 & 454.36 \\
\hline Forestland & 3.43 & 316.35 & 5.24 & 6.48 & - & 0.01 & 331.51 \\
\hline Arable land & 2.35 & 5.57 & 383.86 & 4.70 & - & 0.01 & 396.49 \\
\hline Garden & 2.57 & 2.45 & 3.17 & 125.55 & - & 0.00 & 133.74 \\
\hline Other land & 0.25 & 0.57 & 0.67 & 0.42 & 13.62 & 0.11 & 15.64 \\
\hline Waters & 0.63 & 0.57 & 0.81 & 0.47 & - & 140.69 & 143.17 \\
\hline 2004 total & 369.27 & 345.39 & 420.91 & 155.53 & 17.02 & 166.79 & 1474.91 \\
\hline
\end{tabular}

obtain the transition potential of one land class to another, thereby centered at the core of the cellular automata. The prediction accuracy was acquired from the MLP algorithm. When the accuracy was below $75 \%$, the influencing variables were recalculated or adjusted. In contrast, when the accuracy was above $75 \%$, the transition potential between land use classes was generated. Table 5 lists the calculation results between the transition of each land class to construction land and the influencing variables. The training samples are processed by the MLP method, with a $79.71 \%$ accuracy.

The characteristics and influencing variables of land use transition among various regions from 2008 to 2012 were 


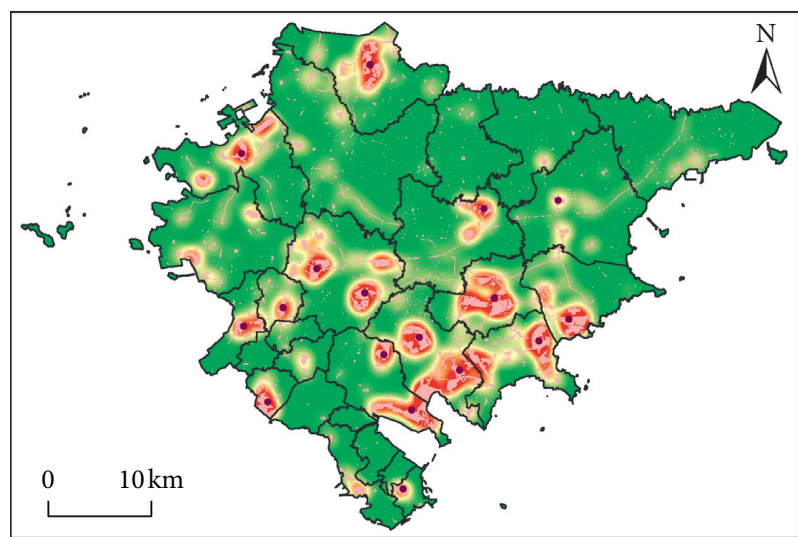

Density

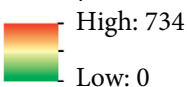

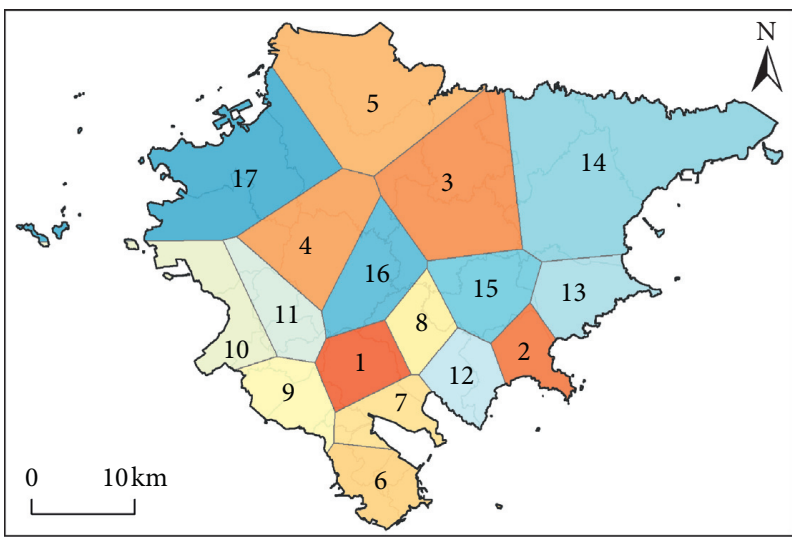

(b)

FIGURE 5: Geospatial partition: (a) Kernel density of land use change; (b) spatial zoning.

TABLE 5: MLP classifier results.

\begin{tabular}{lc}
\hline Variables & Results \\
\hline Hidden layer neurons & 4 \\
Momentum factor & 0.5 \\
Sigmoid constant & 1 \\
Acceptable RMS & 0.01 \\
Iterations & 10000 \\
Training RMS & 0.3882 \\
Testing RMS & 0.3834 \\
Accuracy rate & $79.71 \%$ \\
Skill measure & 0.5942 \\
\hline
\end{tabular}

processed and analyzed using the MLP method to acquire the spatial distribution of the transition potential among different land use classes (Figure 6). Figure 6 indicates that the transition of arable land, forestland, garden, and other land to construction land manifested the land use transition potential in Jinzhou District from 2008 to 2012. The transition potential of arable land was more substantial, where the regions with high transition potential were concentrated in zones 14 and 3 . The regions with high transition potential for forestland were distributed in zones 2, 6, 10, and 12, whereas those with high transition potential for garden were located in zones 4,11 , and 17.

4.3.2. Prediction and Model Validation. The land use transition probability and transition potential were obtained using the MLP-MC model. In this study, the spatially zoned and nonzoned MLP-MC methods were used to predict the land use changes in 2016 (Figures 7(a) and 7(b)). Table 6 presents the comparison of the prediction accuracies. Eventually, the zoning approach was applied to predict land use changes in 2020 (Figure $7(\mathrm{c})$ ). Figure 7 shows that the significant expansion of construction land will be observed in the central and western regions by 2020 , but not in the eastern region due to economic reasons, natural protection, and other factors.

The FoM and Kappa coefficients were used to compare the land use predictions of zoned and nonzoned MLP-MC. Table 6 indicates that the prediction accuracy of the zoned MLP-MC model was higher than that of the nonzoned model. The FoM coefficients of the zoned and nonzoned MLP-MC were 0.27 and 0.34 , respectively, with a difference of 0.07 between them, indicating that the zoned model predictions were more accurate than the nonzoned model predictions. Moreover, the confusion matrix was obtained via the superposition of the predicted and actual land use to calculate the Kappa coefficient for model validation. The Kappa coefficients of the zoned and nonzoned models were 0.87 and 0.95 , respectively, also suggesting that the prediction accuracy of the zoned model was higher than that of the nonzoned model.

\section{Discussion}

Cities are complex and dynamic spatial systems that have the characteristics of both top-down macro-control and bottom-up macro-self-organization during their development, which is the result of the comprehensive action of various forces and resistances. Natural, social, economic, and policy factors influence LUCC [64-67]. To meet the needs of urban planning, we must understand the laws of land use evolution. The simulations of urban growth via cellular automata involve vector and grid models [25, 68]. Different models have different structures, variables, and parameters.

At present, regular grid cells are often used to predict the dynamic characteristics of cities. Previous studies have employed machine learning algorithms combined with cellular automata, such as decision trees, logistic regression, support vector machine, and neural networks, to simulate future land use changes $[69,70]$. However, the unified rules often applied for urban space simulations tend to ignore the 

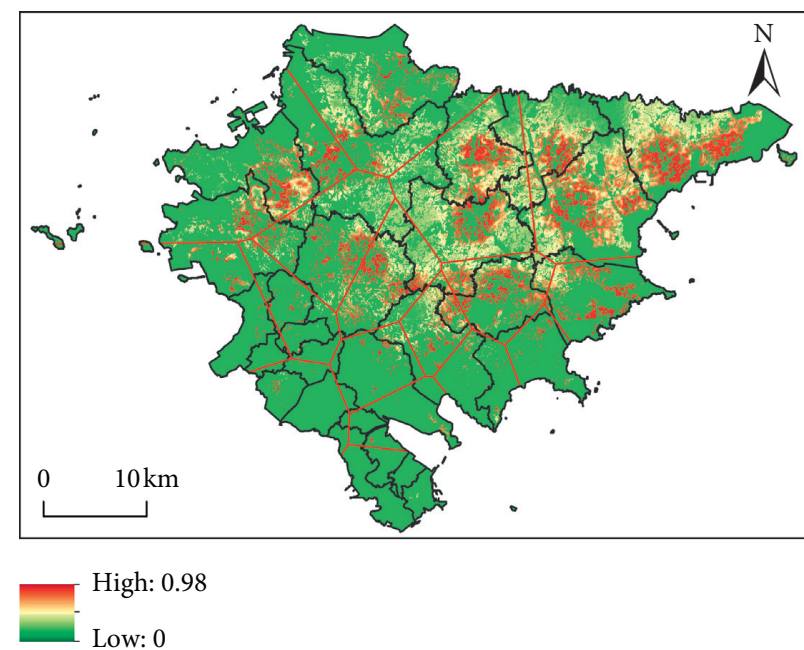

(a)

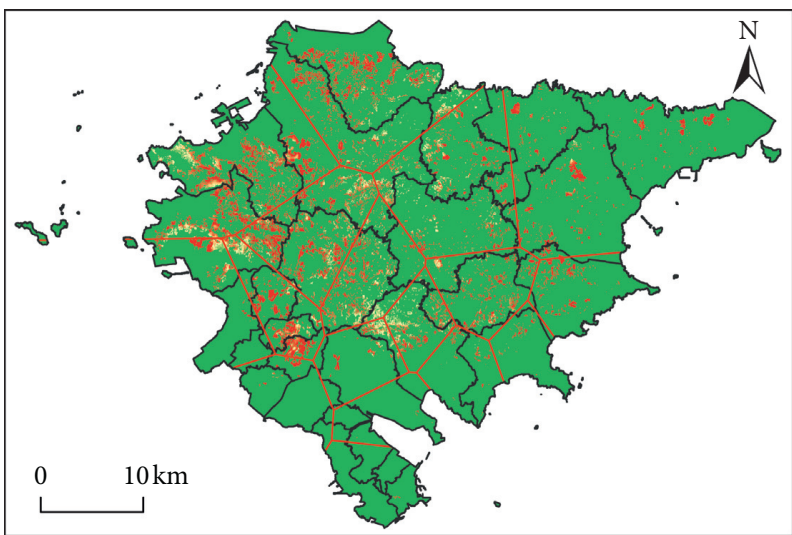

High: 0.98

Low: 0

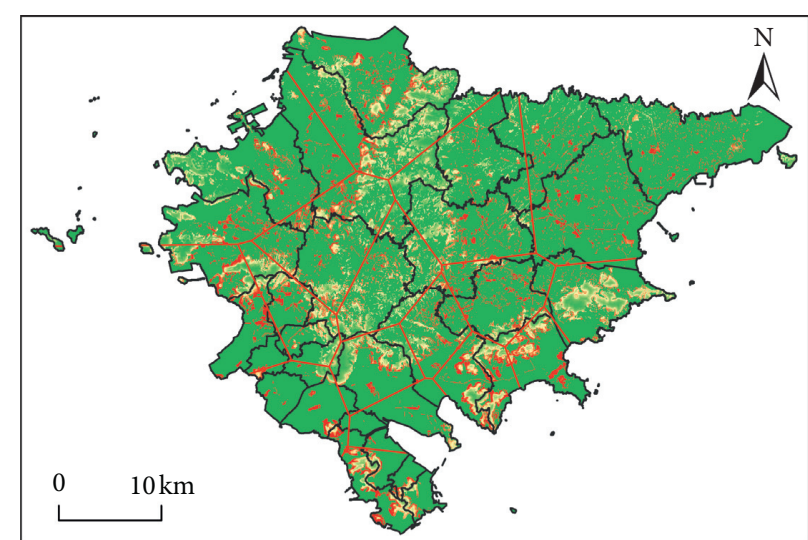

High: 0.97

Low: 0

(b)

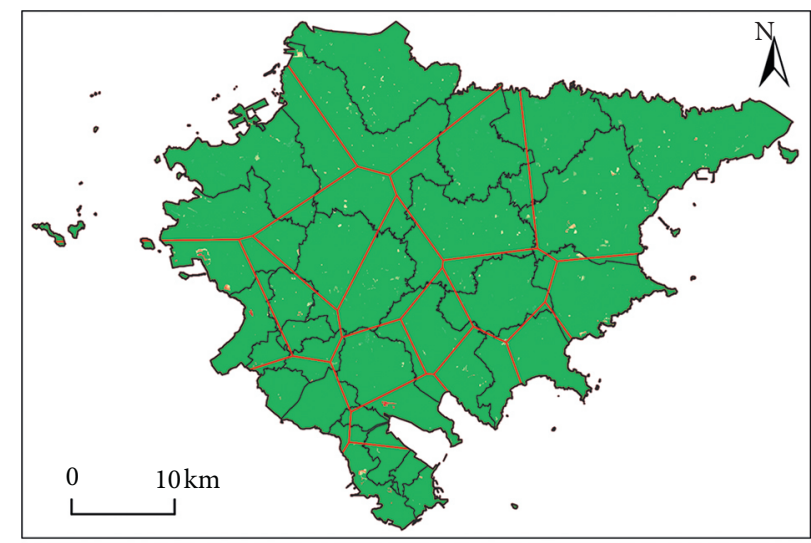

High: 0.99

Low: 0

(d)

(c)

Figure 6: Spatial distribution of land use transfer potential. (a) Arable land to construction land. (b) Forestland to construction land. (c) Garden to construction land. (d) Other land to construction land.

nonstationary spatial characteristics of cities. Thus, dividing the space into homogeneous regions and understanding the conversion rules of each zone is conducive to improving the simulation accuracy.

This study focuses on combining spatial zoning and cellular automata to improve the accuracy of land use simulation. Previous studies on spatial zoning are mostly based on administrative boundaries. Spatial clustering is thus based on factors such as economy, population, and terrain. Moreover, it is easy to ignore the problem of spatial heterogeneity. Therefore, this paper improves simulation accuracy by combining Thiessen polygons and cellular automata to simulate urban land use changes. We combined spatial zoning with the MLP-MC model to obtain the land use conversion rules based on the influencing factors of each zone. Through a comparison with the nonzoned CA model, we were able to more accurately simulate the characteristics of land use change. Combining spatial zoning and CA models not only can effectively predict land use changes but also have application value in regional ecosystem service value and surface temperature simulation.

However, there are certain limitations in our approach. First, when using Thiessen polygons for spatial zoning, the selection of the location and number of points can affect their creation and zoning results and thus the prediction results of the model. Therefore, we must select the appropriate point according to the development characteristics of each zone. Second, this study only used the MLP-MC method to predict land use but did not compare the differences between different models. Third, due to data limitations, the land use data and influencing factors were acquired for a short period. Thus, accurately obtaining the complexity characteristics of urban land use remains a challenge. Therefore, future studies must integrate different zoning approaches and prediction models to examine the complexity of cities. 


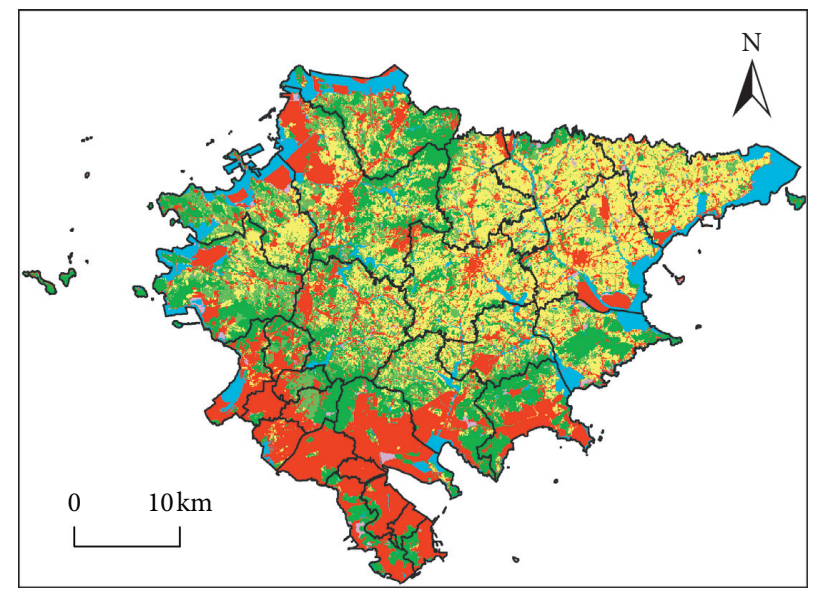

Construction land

Forestland

Arable land
Other lands

Waters

Garden

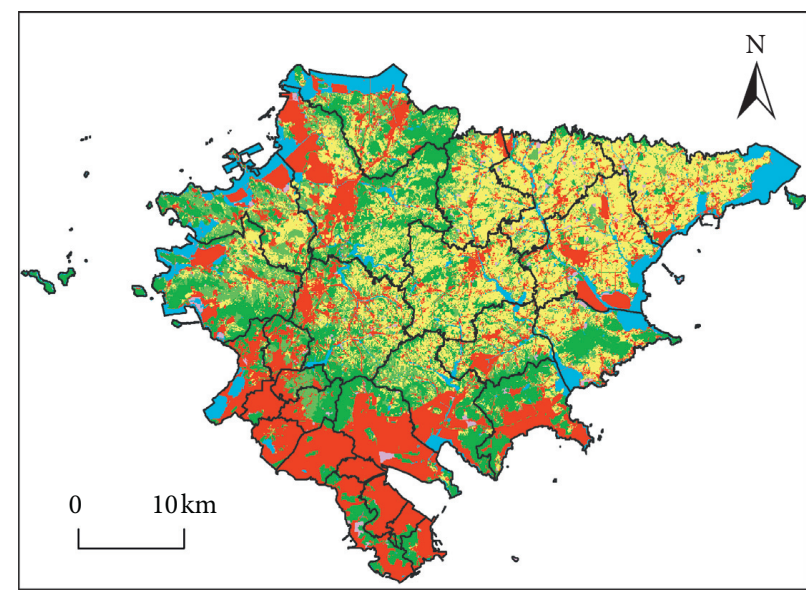

Construction land

Forestland

Arable land
Other lands

Waters

Garden

(b)

(a)

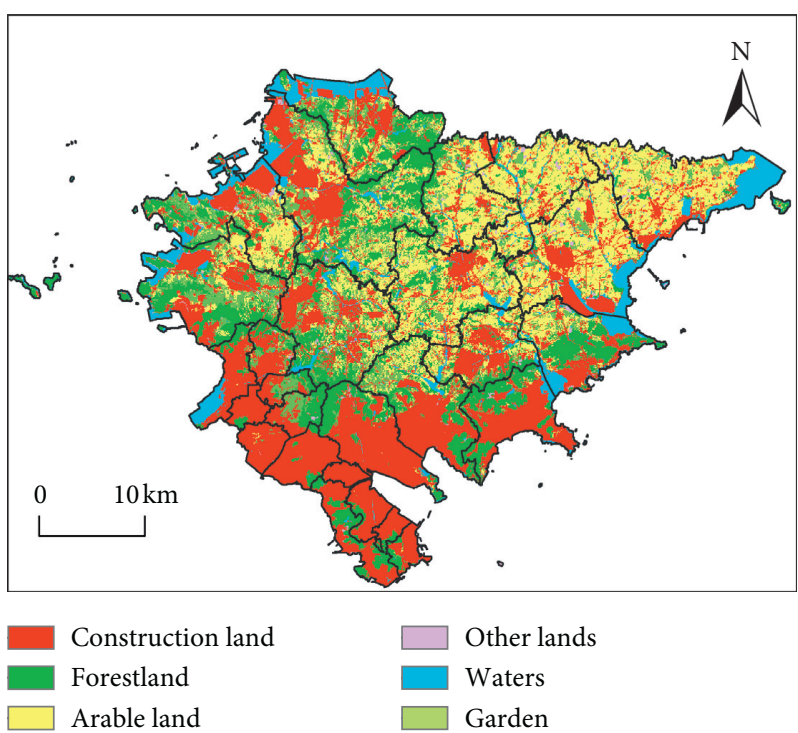

(c)

Figure 7: Land use simulation results. (a) Nonzoning simulation 2016. (b) Zoning simulation 2016. (c) Zoning simulation 2020.

TABle 6: Accuracy comparison of land use simulation.

\begin{tabular}{lccccc}
\hline \multirow{2}{*}{ Model } & \multicolumn{5}{c}{ Statistical value } \\
& Hits & Misses & False alarms & FoM & Kappa \\
\hline Nonsimulation & 9.73 & 14.11 & 11.73 & 0.27 & 0.87 \\
Zoning simulation & 12.12 & 12.78 & 10.67 & 0.34 & 0.95 \\
\hline
\end{tabular}

\section{Conclusions}

Taking Jinzhou District as an example, we used multisource data, such as land use, topography, and social economy, as well as spatial zoning and the MLP-MC model, to predict future dynamic land use changes. From 2004 to 2016, the construction land in Jinzhou District increased by $85.09 \mathrm{~km}^{2}$, whereas arable land and garden decreased by 24.42 and $21.79 \mathrm{~km}^{2}$, respectively. The MLP method was applied to obtain the land use transition potential of each zone to predict future changes. The simulation results showed that the simulation accuracy of zoning was higher than that of nonzoning while the FoM and Kappa coefficients were higher by 0.07 and 0.08 , respectively, in the zoned model than in the nonzoned model. Therefore, the spatial zoning approach chosen to simulate land use changes in this study produce highly accurate predictions. 


\section{Data Availability}

The data used to support the findings of this study are available from the corresponding author upon request.

\section{Conflicts of Interest}

The authors declare that there are no conflicts of interest.

\section{Acknowledgments}

This research study was supported by the National Natural Science Foundation of China (Grant nos. 41771178 and 41630749), Second Tibetan Plateau Scientific Expedition and Research Program (STEP) (Grant no. 2019QZKK1004), and Innovative Talents Support Program of Liaoning Province (Grant no. LR2017017). The authors would like to acknowledge all experts' contributions in the building of the model and the formulation of the strategies in this study.

\section{References}

[1] J. Yang, J. Su, J. Xia, C. Jin, X. Li, and Q. Ge, “The impact of spatial form of urban architecture on the urban thermal environment: a case study of the Zhongshan District, Dalian, China," Ieee Journal of Selected Topics in Applied Earth Observations and Remote Sensing, vol. 11, no. 8, pp. 2709-2716, 2018.

[2] R. A. Pielke, "Land use and climate change," Science, vol. 310, no. 5754, pp. 1625-1626, 2005.

[3] Z. Qiao, L. Liu, Y. Qin, X. Xu, B. Wang, and Z. Liu, "The impact of urban renewal on land surface temperature changes: a case study in the main city of Guangzhou, China," Remote Sensing, vol. 12, no. 5, p. 794, 2020.

[4] B.-J. He, "Towards the next generation of green building for urban heat island mitigation: zero UHI impact building," Sustainable Cities and Society, vol. 50, p. 101647, 2019.

[5] P. Xie, D. Liu, Y. Liu, and Y. Liu, "A least cumulative ventilation cost method for urban ventilation environment analysis," Complexity, vol. 2020, pp. 1-13, 2020.

[6] M. Batty, Cities and Complexity: Understanding Cities with Cellular Automata, Agent-Based Models, and Fractals, The MIT Press, Cambridge, MA, USA, 2007.

[7] R. White and G. Engelen, "Cellular automata and fractal urban form: a cellular modelling approach to the evolution of urban land-use patterns," Environment and Planning A: Economy and Space, vol. 25, no. 8, pp. 1175-1199, 1993.

[8] M. Herold, N. C. Goldstein, and K. C. Clarke, "The spatiotemporal form of urban growth: measurement, analysis and modeling," Remote Sensing of Environment, vol. 86, no. 3, pp. 286-302, 2003.

[9] P. Xie, J. Yang, H. Wang, Y. Liu, and Y. Liu, “A New method of simulating urban ventilation corridors using circuit theory," Sustainable Cities and Society, vol. 59, p. 102162, 2020.

[10] Z.-Q. Zhao, B.-J. He, L.-G. Li, H.-B. Wang, and A. Darko, "Profile and concentric zonal analysis of relationships between land use/land cover and land surface temperature: case study of Shenyang, China," Energy and Buildings, vol. 155, pp. 282-295, 2017.

[11] N. Joshi, M. Baumann, A. Ehammer et al., "A review of the application of optical and radar remote sensing data fusion to land use mapping and monitoring," Remote Sensing, vol. 8, no. 1, p. 70, 2016.
[12] P. Zhang, J. He, X. Hong et al., "Carbon sources/sinks analysis of land use changes in China based on data envelopment analysis," Journal of Cleaner Production, vol. 204, pp. 702-711, 2018.

[13] P. Zhang, Y. Li, W. Jing et al., "Comprehensive assessment of the effect of urban built-up land expansion and climate change on net primary productivity," Complexity, vol. 2020, pp. 1-12, 2020.

[14] J. Ou, X. Liu, X. Li, Y. Chen, and J. Li, "Quantifying spatiotemporal dynamics of urban growth modes in metropolitan cities of China: Beijing, Shanghai, Tianjin, and Guangzhou," Journal of Urban Planning and Development, vol. 143, no. 1, Article ID 04016023, 2017.

[15] M. C. Hansen and T. R. Loveland, "A review of large area monitoring of land cover change using landsat data," Remote Sensing of Environment, vol. 122, pp. 66-74, 2012.

[16] X. Liu, X. Liang, X. Li et al., "A future land use simulation model (FLUS) for simulating multiple land use scenarios by coupling human and natural effects," Landscape and Urban Planning, vol. 168, pp. 94-116, 2017.

[17] G. Chaudhuri and K. C. Clarke, "Modeling an Indian megalopolis-a case study on adapting SLEUTH urban growth model," Computers, Environment and Urban Systems, vol. 77, p. 101358, 2019.

[18] Y. Liang, L. Liu, and J. Huang, "Integrating the SD-CLUE-S and InVEST models into assessment of oasis carbon storage in northwestern China," PLoS One, vol. 12, no. 2, Article ID e0172494, 2017.

[19] D. C. Parker, S. M. Manson, M. A. Janssen, M. J. Hoffmann, and P. Deadman, "Multi-agent systems for the simulation of land-use and land-cover change: a review," Annals of the Association of American Geographers, vol. 93, no. 2, pp. 314-337, 2003.

[20] J. I. Barredo, M. Kasanko, N. McCormick, and C. Lavalle, "Modelling dynamic spatial processes: simulation of urban future scenarios through cellular automata," Landscape and Urban Planning, vol. 64, no. 3, pp. 145-160, 2003.

[21] S. Berberoğlu, A. Akın, and K. C. Clarke, "Cellular automata modeling approaches to forecast urban growth for adana, Turkey: a comparative approach," Landscape and Urban Planning, vol. 153, pp. 11-27, 2016.

[22] J. Kang, L. Fang, S. Li, and X. Wang, "Parallel cellular automata Markov model for land use change prediction over MapReduce framework," Isprs International Journal of GeoInformation, vol. 8, no. 10, p. 454, 2019.

[23] B. Xue, L. Zhang, Y. Geng, B. Mitchell, and W. Ren, "Extended land-use coding system and its application in urban brownfield redevelopment: case study of Tiexi district in Shenyang, China," Journal of Urban Planning and Development, vol. 142, no. 3, p. 05015014, 2016.

[24] M. S. Roodposhti, J. Aryal, and B. A. Bryan, "A novel algorithm for calculating transition potential in cellular automata models of land-use/cover change," Environmental Modelling \& Software, vol. 112, pp. 70-81, 2019.

[25] Y. Zhai, Y. Yao, Q. Guan et al., "Simulating urban land use change by integrating a convolutional neural network with vector-based cellular automata," International Journal of Geographical Information Science, vol. 34, no. 7, pp. 1475-1499, 2020.

[26] J. Liao, L. Tang, G. Shao, X. Su, D. Chen, and T. Xu, "Incorporation of extended neighborhood mechanisms and its impact on urban land-use cellular automata simulations," Environmental Modelling \& Software, vol. 75, pp. 163-175, 2016.

[27] D. Guan, H. Li, T. Inohae, W. Su, T. Nagaie, and K. Hokao, "Modeling urban land use change by the integration of 
cellular automaton and Markov model," Ecological Modelling, vol. 222, no. 20-22, pp. 3761-3772, 2011.

[28] J. J. Arsanjani, M. Helbich, W. Kainz, and A. D. Boloorani, "Integration of logistic regression, markov chain and cellular automata models to simulate urban expansion," International Journal of Applied Earth Observation and Geoinformation, vol. 21, pp. 265-275, 2013.

[29] J. Lin, B. Huang, M. Chen, and Z. Huang, "Modeling urban vertical growth using cellular automata-Guangzhou as a case study,” Applied Geography, vol. 53, pp. 172-186, 2014.

[30] Q. Yang, X. Li, and X. Shi, "Cellular automata for simulating land use changes based on support vector machines," Computers \& Geosciences, vol. 34, no. 6, pp. 592-602, 2008.

[31] X. Li and A. G.-O. Yeh, "Neural-network-based cellular automata for simulating multiple land use changes using GIS," International Journal of Geographical Information Science, vol. 16, no. 4, pp. 323-343, 2002.

[32] C. Gao, Y. Feng, X. Tong, Z. Lei, S. Chen, and S. Zhai, "Modeling urban growth using spatially heterogeneous cellular automata models: comparison of spatial lag, spatial error and GWR," Computers, Environment and Urban Systems, vol. 81, Article ID 101459, 2020.

[33] J. Yang, W. Liu, Y. Li, X. Li, and Q. Ge, "Simulating intraurban land use dynamics under multiple scenarios based on fuzzy cellular automata: a case study of Jinzhou district, Dalian," Complexity, vol. 2018, Article ID 7202985, 17 pages, 2018.

[34] D. Gounaridis, I. Chorianopoulos, E. Symeonakis, and S. Koukoulas, "A random forest-cellular automata modelling approach to explore future land use/cover change in Attica (Greece), under different socio-economic realities and scales," Science of the Total Environment, vol. 646, pp. 320-335, 2019.

[35] Y. Feng and X. Tong, "Dynamic land use change simulation using cellular automata with spatially nonstationary transition rules," GIScience \& Remote Sensing, vol. 55, no. 5, pp. 678-698, 2018.

[36] J. Yang, A. Guo, Y. Li, Y. Zhang, and X. Li, "Simulation of landscape spatial layout evolution in rural-urban fringe areas: a case study of Ganjingzi District," GIScience \& Remote Sensing, vol. 56, no. 3, pp. 388-405, 2019.

[37] C. Xia, A. Zhang, H. Wang, and B. Zhang, "Modeling urban growth in a metropolitan area based on bidirectional flows, an improved gravitational field model, and partitioned cellular automata," International Journal of Geographical Information Science, vol. 33, no. 5, pp. 877-899, 2019.

[38] J. Yang, C. Zeng, and Y. Cheng, "Spatial influence of ecological networks on land use intensity," Science of the Total Environment, vol. 717, Article ID 137151, 2020.

[39] D. Zhang, X. Liu, X. Wu, Y. Yao, X. Wu, and Y. Chen, "Multiple intra-urban land use simulations and driving factors analysis: a case study in Huicheng, China," GIScience \& Remote Sensing, vol. 56, no. 2, pp. 282-308, 2018.

[40] P. Tripathy and A. Kumar, "Monitoring and modelling spatiotemporal urban growth of Delhi using cellular automata and geoinformatics," Cities, vol. 90, pp. 52-63, 2019.

[41] X. Fu, X. Wang, and Y. J. Yang, "Deriving suitability factors for CA-Markov land use simulation model based on local historical data," Journal of Environmental Management, vol. 206, pp. 10-19, 2018.

[42] X. Huang, X. Huang, M. Liu, B. Wang, and Y. Zhao, "Spatialtemporal dynamics and driving forces of land development intensity in the western China from 2000 to 2015," Chinese Geographical Science, vol. 30, no. 1, pp. 16-29, 2020.

[43] Y. Qian, W. Xing, X. Guan, T. Yang, and H. Wu, "Coupling cellular automata with area partitioning and spatiotemporal convolution for dynamic land use change simulation," Science of the Total Environment, vol. 722, Article ID 137738, 2020.

[44] X. Ke, L. Qi, and C. Zeng, "A partitioned and asynchronous cellular automata model for urban growth simulation," International Journal of Geographical Information Science, vol. 30, no. 4, pp. 637-659, 2016.

[45] A. Kazemzadeh-Zow, S. Zanganeh Shahraki, L. Salvati, and N. N. Samani, "A spatial zoning approach to calibrate and validate urban growth models," International Journal of Geographical Information Science, vol. 31, no. 4, pp. 763-782, 2017.

[46] J. Shen, X. Liu, and M. Chen, "Discovering spatial and temporal patterns from taxi-based floating car data: a case study from Nanjing," GIScience \& Remote Sensing, vol. 54, no. 5, pp. 617-638, 2017.

[47] B. Wilebore and D. Coomes, "Combining spatial data with survey data improves predictions of boundaries between settlements," Applied Geography, vol. 77, pp. 1-7, 2016.

[48] M. E. Mirici, S. Berberoglu, A. Akin, and O. Satir, "Land use/ cover change modelling in a Mediterranean rural landscape using multi-layer perceptron and Markov chain (MLP-MC)," Applied Ecology and Environmental Research, vol. 16, no. 1, pp. 467-486, 2017.

[49] R. Hamad, H. Balzter, and K. Kolo, "Predicting land use/land cover changes using a CA-Markov model under two different scenarios," Sustainability, vol. 10, no. 10, p. 3421, 2018.

[50] Q. Guan, L. Wang, and K. C. Clarke, "An artificial-neuralnetwork-based, constrained CA model for simulating urban growth," Cartography and Geographic Information Science, vol. 32, no. 4, pp. 369-380, 2005.

[51] W. Qiao, J. Gao, Y. Liu, Y. Qin, C. Lu, and Q. Ji, "Evaluation of intensive urban land use based on an artificial neural network model: a case study of Nanjing City, China," Chinese Geographical Science, vol. 27, no. 5, pp. 735-746, 2017.

[52] H. Wu, Z. Li, K. C. Clarke et al., "Examining the sensitivity of spatial scale in cellular automata Markov chain simulation of land use change," International Journal of Geographical Information Science, vol. 33, no. 5, pp. 1040-1061, 2019.

[53] J. Xia, P. Zeephongsekul, and D. Packer, "Spatial and temporal modelling of tourist movements using Semi-Markov processes," Tourism Management, vol. 32, no. 4, pp. 844-851, 2011.

[54] P. M. Atkinson and A. R. L. Tatnall, "Introduction neural networks in remote sensing," International Journal of Remote Sensing, vol. 18, no. 4, pp. 699-709, 1997.

[55] H. Yuan, C. Van Der Wiele, and S. Khorram, "An automated artificial neural network system for land use/land cover classification from Landsat TM imagery," Remote Sensing, vol. 1, no. 3, pp. 243-265, 2009.

[56] H. Omrani, A. Tayyebi, and B. Pijanowski, "Integrating the multi-label land-use concept and cellular automata with the artificial neural network-based Land Transformation Model: an integrated ML-CA-LTM modeling framework," GIScience \& Remote Sensing, vol. 54, no. 3, pp. 283-304, 2017.

[57] L. Ott, R. F. Larson, and W. Mendenhall, Statistics: a Tool for the Social Sciences, Duxbury Press, Boston, MA, USA, 1983.

[58] C. Mozumder and N. K. Tripathi, "Geospatial scenario based modelling of urban and agricultural intrusions in Ramsar wetland Deepor Beel in Northeast India using a multi-layer perceptron neural network," International Journal of Applied Earth Observation and Geoinformation, vol. 32, pp. 92-104, 2014.

[59] R. G. Pontius, W. Boersma, J.-C. Castella et al., "Comparing the input, output, and validation maps for several models of 
land change," The Annals of Regional Science, vol. 42, no. 1, pp. 11-37, 2008.

[60] R. G. Pontius Jr., R. Walker, R. Yao-Kumah et al., “Accuracy assessment for a simulation model of Amazonian deforestation," Annals of the Association of American Geographers, vol. 97, no. 4, pp. 677-695, 2007.

[61] Y. He, B. Ai, Y. Yao, and F. Zhong, "Deriving urban dynamic evolution rules from self-adaptive cellular automata with multi-temporal remote sensing images," International Journal of Applied Earth Observation and Geoinformation, vol. 38, pp. 164-174, 2015.

[62] R. G. Pontius, "Quantification error versus location error in comparison of categorical maps," Photogrammetric Engineering and Remote Sensing, vol. 66, no. 8, pp. 1011-1016, 2000.

[63] W. Wang, L. Jiao, T. Dong, Z. Xu, and G. Xu, "Simulating urban dynamics by coupling top-down and bottom-up strategies," International Journal of Geographical Information Science, vol. 33, no. 11, pp. 2259-2283, 2019.

[64] M. Jiao, M. Hu, and B. Xia, "Spatiotemporal dynamic simulation of land-use and landscape-pattern in the Pearl River Delta, China," Sustainable Cities and Society, vol. 49, Article ID 101581, 2019.

[65] M. Zare, T. Panagopoulos, and L. Loures, "Simulating the impacts of future land use change on soil erosion in the Kasilian watershed, Iran," Land Use Policy, vol. 67, pp. 558572, 2017.

[66] H. W. Zheng, G. Q. Shen, H. Wang, and J. Hong, "Simulating land use change in urban renewal areas: a case study in Hong Kong," Habitat International, vol. 46, pp. 23-34, 2015.

[67] S. Jin, J. Yang, E. Wang, and J. Liu, "The influence of highspeed rail on ice-snow tourism in Northeastern China," Tourism Management, vol. 78, p. 104070, 2020.

[68] P. Barreira-González, M. Gómez-Delgado, and F. AguileraBenavente, "From raster to vector cellular automata models: a new approach to simulate urban growth with the help of graph theory," Computers, Environment and Urban Systems, vol. 54, pp. 119-131, 2015.

[69] H. Shafizadeh-Moghadam, "Improving spatial accuracy of urban growth simulation models using ensemble forecasting approaches," Computers, Environment and Urban Systems, vol. 76, pp. 91-100, 2019.

[70] Y. Yao, X. Liu, X. Li et al., "Simulating urban land-use changes at a large scale by integrating dynamic land parcel subdivision and vector-based cellular automata," International Journal of Geographical Information Science, vol. 31, no. 12, pp. 24522479, 2017. 